\title{
A Possible Role of Therapeutic Drug Monitoring in Virological Breakthrough during Simeprevir and PEG-IFN Treatment in HCV-4
}

\author{
Lucio Boglione Tina Ruggiero Amedeo De Nicolò Antonio D’Avolio Giovanni Di Perri \\ Unit of Infectious Diseases, Department of Medical Sciences, Amedeo di Savoia Hospital, University of Turin, \\ Turin, Italy
}

Dear Editor,

According to EASL guidelines, treatments for GT4 infection are currently based on peginterferon- $\alpha$ (PEG-IFN $\alpha$ ) plus ribavirin with simeprevir (SMV) or sofosbuvir. Also available are the IFN-free regimens with sofosbuvir and ledipasvir, sofosbuvir and SMV, sofosbuvir and daclatasvir, and ombitasvir plus paritaprevir/ritonavir and ribavirin [1]. However, limited data about the efficacy of these treatments on GT4 are available. In addition, the role of resistance-associated variants (RAVs) in directing acting antiviral agents in this genotype has not been explored deeply and needs further investigation [2].

Available data concerning viral breakthrough (BT) in GT4 patients treated with
PEG-IFNa plus ribavirin and SMV were reported in the RESTORE study, a phase III, open label, single-arm study where $20 / 107$ patients $(18.7 \%)$ evidenced a virological failure due to the occurrence of RAVs; this rate was lower in naïve patients $(11.4 \%)$ and higher in prior null responders (32.5\%) [3]. D168V and D168E were the most frequently observed RAVs in $\mathrm{BT}$ patients $(75 \%)$. We recently published an article on the role of therapeutic drug monitoring (TDM) of boceprevir in treatment failure [4] in GT1 patients, while to our knowledge no data have been provided concerning the role of SMV plasma concentration in the selection of RAVs.
We reported a single case of a HCV-4 patient (subtype $4 \mathrm{~d}$ ) treated with a triple combination of PEG-IFNa plus ribavirin and SMV, with subsequent BT. This patient had a METAVIR score of F1 and the treatment included PEG-IFNa $\alpha_{2 b} 100 \mu \mathrm{g} /$ week, ribavirin $1,000 \mathrm{mg} / \mathrm{day}$, and SMV $150 \mathrm{mg} /$ day.

Despite a higher HCV-RNA decrease after 2 weeks and undetectability after 1 month of treatment (rapid virological response), at the third month HCV-RNA was detectable again. The BT was confirmed by NS3 analysis that evidenced the selection of the SMV-resistant variant D168V; the same test showed a wild-type NS3 region at the baseline. The quantification of SMV in

Table 1. Biochemical and virological parameters during treatment (weeks) with PEG-IFNa plus ribavirin and simeprevir

\begin{tabular}{|c|c|c|c|c|c|c|}
\hline & Baseline & Wk 2 & Wk 4 & Wk 8 & Wk 12 & Wk 16 \\
\hline ALT, IU/L & 166 & 45 & 22 & 29 & 44 & 61 \\
\hline $\mathrm{Hb}, \mathrm{g} / \mathrm{L}$ & 16.7 & 13.2 & 12.5 & 12.1 & 12.2 & 14.1 \\
\hline Simeprevir plasma concentration, $\mathrm{ng} / \mathrm{mL}$ & & & 320 & 100 & 25 & \\
\hline Ribavirin plasma concentration, $\mathrm{ng} / \mathrm{mL}$ & & & 1,659 & 1,819 & 1,401 & \\
\hline HCV-RNA, IU/mL & $4,330,207$ & 23 & NEG & NEG & 11,848 & 408,350 \\
\hline HCV NS3 variants & wild-type & & & & D168V & \\
\hline
\end{tabular}

Wk, week; ALT, alaninoaminotransferase; Hb, hemoglobin; NEG, negative.

\section{KARGER}

(C) 2017 S. Karger AG, Basel

E-Mail karger@karger.com

www.karger.com/int
Lucio Boglione

Amedeo di Savoia Hospital

C.so Svizzera 164

IT-10149 Turin (Italy)

E-Mail lucio.boglione@unito.it 
plasma was performed though our previously published method [5].

Interestingly, we observed a much lower SMV level at the time of BT $(25 \mathrm{ng} / \mathrm{mL})$ than that observed in subjects without BT (Table 1).

The TDM of SMV and ribavirin confirmed the self-reported adherence of the patient. However, the SMV concentration at the time of BT was lower than that at the start of therapy ( 320 vs. $25 \mathrm{ng} / \mathrm{mL}$ ). The cause of this low SMV concentration is still unknown: the adherence to treatment was high, as demonstrated by the TDM of ribavirin; moreover, the once-daily intake of SMV encouraged the adherence to treatment. This patient did not report the intake of any concomitant drug or herbal medication with a possible inducing effect on $\mathrm{cy}$ -

References tochromes and was not treated before with first-generation protease inhibitors.

The only evidence concerned a progressive lowering of SMV plasma concentrations, probably underlying a sort of "selfinduction" of CYP3A4 by SMV itself; moreover, the magnitude of this phenomenon could be affected by genetic polymorphisms on genes encoding drug transporters (such as P-glycoprotein) and metabolizing enzymes (such as CYP3A4). This experience provides evidence that TDM could be a useful tool during treatment with SMV in order to prevent virological failure with the closing plasma concentration measurement. Further studies are required to confirm this interesting role in SMV-based regimens or with other antiviral drugs.

1 EASL: EASL Recommendations on Treatment of Hepatitis C 2015. http://www.easl.eu/ medias/cpg/HEPC-2015/Full-report.pdf.

2 Abdel-Razek W, Waked I: Optimal therapy in genotype 4 chronic hepatitis $\mathrm{C}$ : finally cured? Liver Int 2014;35(suppl 1):27-34.

3 Moreno C, Hezode C, Marcellin P, Bourgeois S, Francque S, Samuel D, et al: Efficacy and safety of simeprevir with PegIFN/ribavirin in naive or experienced patients infected with chronic HCV genotype 4. J Hepatol 2015;62: 1047-1055.

\section{Statement of Ethics}

The "Kinetic-C Study" was approved by our local ethics committee on May 26, 2015.

\section{Disclosure Statement}

The authors disclose no conflicts of interest.

\section{Funding Sources}

This study was supported by internal funding.

4 Boglione L, De Nicolo A, Cardellino CS, Ruggiero T, Ghisetti V, Cariti G, et al: Relationship between the early boceprevir-S isomer plasma concentrations and the onset of breakthrough during HCV genotype 1 triple therapy. Clin Microbiol Infect 2015;21:205.e1-e3.

5 Ariaudo A, Favata F, De Nicolò A, Simiele M, Paglietti L, Boglione L, et al: A UHPLC-MS/ MS method for the quantification of direct antiviral agents simeprevir, daclatasvir, ledipasvir, sofosbuvir/GS-331007, dasabuvir, ombitasvir, and paritaprevir, together with ritonavir, in human plasma. J Pharm Biomed Anal 2016;125:369-375. 